\title{
Potential drug incompatibilities in the neonatal intensive care unit: a network analysis approach
}

\author{
Ramon Weyler Leopoldino ${ }^{1^{*}} \mathbb{D}$, Haline Tereza Costa ${ }^{1}$, Tatiana Xavier Costa $^{2}$, Rand Randall Martins ${ }^{1}$ and \\ António Gouveia Oliveira ${ }^{1}$
}

\begin{abstract}
Background: There is little information on the frequency of drug incompatibilities in neonatal intensive care units (NICU) and the agents most commonly involved in them. The objective of the study was to characterize potential Drug Incompatibilities (DI) in the NICU by frequency, type and combination of drugs.

Methods: Between August 2015 and December 2016, all neonates admitted for more than $24 \mathrm{~h}$ and who received any drug treatment were included in this cohort study conducted in the NICU of a teaching maternity hospital in Brazil. Patient data were collected from patient records and prescription orders, and the compatibilities of all drug pairs were classified using the Trissel's ${ }^{\mathrm{TM}} 2$ IV Compatibility tool. Network analysis was performed in order to visualize the drug pairs commonly involved in potential DI.

Results: The study population consisted of 281 neonates with a median NICU length of stay of 11 days (range 2-184) and received 1343 intravenous medications. A total of 1114 potential DI were identified, 469 (42.1\%) were restricted compatibilities, 348 (31.2\%) unknown compatibilities and 297 (26.7\%) documented incompatibilities. The incidence of documented incompatibilities in the NICU was $25.0 \%$ patient-days (95\% confidence interval (Cl) 19.4-30.7\% patient-days). Incompatible potential DI affected $46.3 \%(95 \% \mathrm{Cl} 40.3-52.3 \%)$ of the neonates. Ampicillin (408 of 1114 pairs), gentamicin (216 of 1114 pairs) and aminophylline (197 of 1114 pairs) were the main medicines involved in potential DI.

Conclusion: Potential DI are extremely common in NICU, with half of the population susceptible to simultaneous administration of incompatible medications. More research is needed to understand the actual drug incompatibilities and their clinical outcomes.
\end{abstract}

Keywords: Infant, newborn, Critical care, Drug incompatibility, Patient safety, Network analysis

\section{Background}

Drug Incompatibility (DI) is a reaction between an intravenous drug and the diluent, container or other intravenous drug, causing visible changes or degradation of more than $10 \%$ of the drug $[1,2]$. Incompatibilities are classified as physical or chemical [1]. Usually readily visible, physical incompatibility reactions are rapid, reversible and can cause precipitate formation, gas release, or changes in

\footnotetext{
* Correspondence: ramon.weyler@gmail.com

1Department of Pharmacy, Centro de Ciências da Saúde, Universidade Federal do Rio Grande do Norte, Av. General Gustavo Cordeiro de Farias, s/n. Petrópolis, Natal, RN 59012-570, Brazil

Full list of author information is available at the end of the article
}

viscosity and color [1, 3]. In contrast, drug degradation through chemical incompatibility is predominantly slow, irreversible and not visible as hydrolysis, oxidation or covalent reaction $[1,3]$.

DI can compromise drug effectiveness and/or patient safety [1]. For example, Foinard et al. [4] observed that concurrent administration of furosemide $(10 \mathrm{mg} / \mathrm{ml})$ and midazolam $(1 \mathrm{mg} / \mathrm{ml})$ at the same infusion rate $(2 \mathrm{mg} / \mathrm{h})$ resulted in $14 \%$ furosemide precipitation. The precipitate formed can reach the bloodstream and compromise tissue perfusion and function of vital organs [5]. Moreover, there fatal cardiopulmonary complications due to precipitation

(c) The Author(s). 2018 Open Access This article is distributed under the terms of the Creative Commons Attribution 4.0 International License (http://creativecommons.org/licenses/by/4.0/), which permits unrestricted use, distribution, and reproduction in any medium, provided you give appropriate credit to the original author(s) and the source, provide a link to the Creative Commons license, and indicate if changes were made. The Creative Commons Public Domain Dedication waiver (http://creativecommons.org/publicdomain/zero/1.0/) applies to the data made available in this article, unless otherwise stated. 
between ceftriaxone and calcium electrolyte solutions have been documented in neonates [6].

In the hospital setting, reactions between medications (actual drug incompatibility) are poorly observed, but circumstances that favor contact between incompatible medications or between medication with poorly documented compatibility (potential drug incompatibility) are common [7-9]. A Canadian study involving 434 intensive care adults showed a potential DI prevalence of $8.5 \%$ [10]. Another Canadian study found a potential DI prevalence of $52 \%$ in more than 16,000 pediatric patients [11].

It is believed that neonates in the Neonatal Intensive Care Unit (NICU) have greater exposure to DI, as compared to adult patients. Neonates typically have a single access route for intravenous administration, which increases the chance of drug mixing. Additionally, the volume of diluents is smaller and the infusion rate is slower than in adults, which might lead to high concentrations and prolonged contact time between incompatible drugs [12]. However, information on the frequency and type of DI within the NICU is lacking.

As a contribution to closing this knowledge gap, the objective of this study was to characterize potential DI in NICU according to their frequency, type and to identify the most common inappropriate combination of drugs through network analysis.

\section{Methods}

This prospective cohort study was conducted during a 17-month period, from August 2015 to December 2016, in the 20-bed NICU of a teaching maternity hospital specialized in high-risk pregnancy, in Brazil. All neonates admitted to the NICU for more than $24 \mathrm{~h}$ and who received drug treatment were included in the study.

The data were collected from the clinical patient records and the prescription orders. Clinical and demographic data (sex, gestational age, birth weight and length of stay) were recorded from every newborn included in the study, as well as every intravenous medication prescribed throughout NICU stay. Electrolyte and parenteral nutrition solutions, diagnostic agents and vitamin and mineral supplements were not considered as medicines.

A daily evaluation of the compatibility of all prescribed drugs of each neonate was done with the Trissel's ${ }^{\text {sm }} 2$ IV Compatibility tool available in the Micromedex ${ }^{\circ}$ database (Truven Health Analytics, Michigan, USA). A potential DI was defined as the prescription of two intravenous medicines that were not documented to be compatible. Potential DI were classified according to the quality of the compatibility studies performed: incompatible (welldocumented drug interaction), restricted compatibility by concentration and diluent (discordant drug compatibility data), and unknown (no compatibility data). The pairs of incompatible medicines were classified according to the physicochemical mechanism of the reactions as precipitation, turbidity, decomposition and color change. All identified potential DI were reported to the NICU healthcare team for appropriate action.

\section{Statistical analysis}

The data are described as mean \pm standard deviation, absolute and relative frequencies, and median and range as appropriate in each case. Potential DI prevalence was defined as the proportion of patients with at least one potential DI during the NICU stay and presented as point estimates and exact $95 \%$ confidence intervals (CI). Potential DI incidence is presented as incidence density and defined as number of potential DI as \% patient-days with Poisson 95\% CI. The risk of potential DI associated with the medicines most commonly involved in potential DI was estimated with logistic regression and presented as odds-ratios (OR) with 95\% confidence intervals (CI). The analysis was performed with Stata $^{\circ} 13$ (Stata Corporation, College Station, TX, USA). A network analysis was carried out using Gephi 0.9.1 [13] to visualize the medicines and the pairs commonly involved in potential DI. For this analysis, the ForceAtlas2 algorithm [14] was applied.

\section{Results}

During the study period, 430 neonates were admitted to the NICU and 104 of those were excluded because of NICU stay $<24 \mathrm{~h}$ (95 patients) or because they had no drugs prescribed (9 patients). From the 326 neonates included in the study, 45 (13.8\%) were excluded from the analysis because of missing relevant data items. Therefore, the analysis set included 281 patients that were observed for a total of 5495 days, consisting of $57.3 \%$ males, with mean gestational age of $32.6 \pm$ 3.9 weeks and mean birth weight of $1956.5 \pm 910.9 \mathrm{~g}$. The median NICU length of stay was 11 days (range 2184 days). A total of 1343 intravenous medications were prescribed, representing a mean of $4.8 \pm 3.7$ medications per patient. The most prescribed intravenous medicines, administered to 259 (92.2\%) neonates, were gentamicin, ampicillin, aminophylline, fentanyl, cefepime and amikacin. The mortality rate in the NICU was $7.1 \%$ (20 deaths). Demographic and clinical characteristics of the study population are summarized in Table 1. Two hundred fifty-nine neonates.

A total of 1114 potential DI were identified, representing an average of $19.6 \pm 36.4$ potential DI per patient. Of these, $469(42.1 \%)$ were restricted compatibility, 348 (31.2\%) were unknown compatibility and 297 (26.7\%) documented incompatibilities. Two hundred and ten 
Table 1 Characteristics of the study population $(n=281)$

\begin{tabular}{lll}
\hline Demographic and clinical characteristics & Value & \\
\hline Male sex $(n, \%)$ & 161 & 57.3 \\
Gestational age in weeks (m, sd) & 32.6 & 3.9 \\
Birth weight in grams (m, sd) & 1956.5 & 910.9 \\
Length of stay in days (median, range) & 11 & $2-184$ \\
Number of intravenous drugs (m, sd) & 4.8 & 3.7 \\
Intravenous medicines ( $n, \%)$ & & \\
Gentamicin & 226 & 16.8 \\
Ampicillin & 158 & 11.8 \\
Aminophylline & 149 & 11.1 \\
Fentanyl & 114 & 8.5 \\
Cefepime & 70 & 5.2 \\
Amikacin & 69 & 5.1 \\
Other & 557 & 41.5 \\
Death $(n, \%)$ & 20 & 7.1 \\
\hline
\end{tabular}

$m$ mean, sd standard deviation, $\mathrm{Cl}$ confidence interval

(74.1, 95\% CI 69.2-79.7\%) neonates had at least one potential DI. The incidence of potential DI was $99.9 \%$ patient-days (95\% CI $80.9-118.9 \%$ patient-days). The prevalence and incidence of neonates with incompatible potential DI was $46.3 \%$ (95\%CI $40.3-52.3 \%$ ) and $25.0 \%$ patient-days (95\%CI $19.4-30.7 \%$ patient-days), respectively. Table 2 has more information about the frequency and characteristics of potential DI.

The most frequent pairs of medicines with potential DI are shown in Table 3. The most frequent pairs were Ampicillin - Gentamicin (158, 14.12\%), Aminophylline Ampicillin (77, 6.91\%) and Ampicillin - Fentanyl, (61, $5.48 \%$ ). The median (range) exposure time to each drug pair was 6 days ( $1-13$ days), 5 days ( $1-11$ days) and 5 days (1-11 days), respectively.

Figure 1 shows the network analysis of the main medicines involved in potential DI. This figure contains eight nodes (representing the main medicines involved) and ten ties (representing drug combinations). Ampicillin (408 of 1114 pairs), gentamicin (216 of 1114 pairs) and aminophylline (197 of 1114 pairs) were the medicines most involved in potential DI. The estimates of the risk of occurrence of potential DI for the medicines most often implicated were the following: ampicillin (OR 30.9, 95\% CI 14.3-67.7), gentamicin (OR 3.3, 95\% CI 2.6-4.6), aminophylline (OR 5.0, 95\% CI 4.0-7.2), dobutamine (OR 1.3, 95\% CI 1.1-1.7), furosemide (OR 74.5, 95\% CI 34.4-161.0) and fentanyl (OR 4.9, 95\% CI 3.6-6.6).

\section{Discussion}

Our main findings indicate that about $80 \%$ of newborns are exposed to potential DI during their stay in the NICU, with an expectation of one potential DI per patient each day. We also found that half of the neonates had at least one potential DI well documented in the literature. Other important results were restricted compatibility and that Ampicillin-Gentamicin was the most common drug pair and also the most common potential DI. The medicines most involved in potential DI were ampicillin, gentamicin and aminophylline.

Very few studies have looked into the characteristics of potential DI in pediatrics. As far as we know, only five papers have studied potential DI in hospitalized children, as the majority of potential DI papers in pediatrics are population-based studies. A retrospective study evaluated more than 16 thousand children between 2006 and 2015 [11], and the other works were cross-sectional surveys conducted in less than 1 year $[15,16]$. All the authors identified potential DI through the analysis of the medication orders, only Gikic and collaborators [7] evaluate in loco the occurrence of incompatibilities at the moment of infusion. Works of this nature need adequate sources for the characterization of potential DI. For example, Trissel's Handbook on injectable drugs is the main reference for several authors $[7,9,11,15,16]$.

Evaluating prospectively close to 300 newborns, we observed that nearly half of these patients had prescriptions with potential DI well described in the literature. Gaetani et al. [11], with a retrospective study in a large pediatric population not including neonates, observed an equivalent prevalence.

The most observed potential DI in our study was compatibility with restriction by concentration and diluent. In contrast, several authors showed unknown

Table 2 Frequency and characterization of potential Drug Incompatibilities (DI) in Neonatal Intensive Care

\begin{tabular}{llll}
\hline Potential DI & $\begin{array}{l}\text { Combinations } \\
n(\%)\end{array}$ & $\begin{array}{l}\text { Prevalence } \\
n(\% ; 95 \% C l)\end{array}$ & $\begin{array}{l}\text { Incidence } \\
\% \text { patient-days (95\%Cl) }\end{array}$ \\
\hline Restricted $^{\mathrm{a}}$ & $469(42.1)$ & $195(69.4 ; 63.6-74.7)$ & $41.7(35.1-48.4)$ \\
Unknown $^{b}$ & $348(31.2)$ & $84(29.9 ; 24.6-35.6)$ & $33.1(22.7-43.6)$ \\
Incompatible $^{c}$ & $297(26.7)$ & $130(46.3 ; 40.3-52.3)$ & $25.0(19.4-30.7)$ \\
Total & $1114(100.0)$ & $210(74.7 ; 69.2-79.7)$ & $99.9(80.9-118.9)$ \\
\hline
\end{tabular}

$\mathrm{Cl}$ confidence interval

${ }^{a}$ Drug compatibility with restriction by concentration and diluent

${ }^{b}$ Drug compatibility without compatibility data

'Drug incompatibilities well documented in the literature 
Table 3 Frequency, days of prescriptions and interaction characteristics of medicine pairs with potential Drug Incompatibility

\begin{tabular}{|c|c|c|c|c|c|}
\hline \multirow[t]{2}{*}{ Medicine pairs } & \multirow[t]{2}{*}{ Number } & \multirow[t]{2}{*}{ Percent } & \multicolumn{2}{|c|}{ Days of prescriptions } & \multirow{2}{*}{$\begin{array}{l}\text { Interaction } \\
\text { characteristics }\end{array}$} \\
\hline & & & Median & Range & \\
\hline Ampicillin - Gentamicin & 158 & 14.2 & 6 & $1-13$ & A \\
\hline Aminophylline - Ampicillin & 77 & 6.91 & 5 & $1-11$ & $E$ \\
\hline Ampicillin - Fentanyl & 61 & 5.48 & 5 & $1-11$ & A \\
\hline Cefepime - Fentanyl & 35 & 3.14 & 5 & $1-11$ & B \\
\hline Aminophylline - Cefepime & 32 & 2.87 & 5 & $1-10$ & B \\
\hline Aminophylline - Dobutamine & 28 & 2.51 & 3 & $1-18$ & $\mathrm{D}$ \\
\hline Ampicillin - Dobutamine & 26 & 2.33 & 3 & $1-10$ & C \\
\hline Furosemide - Gentamicin & 26 & 2.33 & 2 & $1-10$ & A \\
\hline Fentanyl - Meropenem & 25 & 2.24 & 9 & $2-18$ & B \\
\hline Dobutamine - Furosemide & 23 & 2.06 & 4 & $1-48$ & A \\
\hline Total & 1114 & 100.00 & 8 & $1-48$ & - \\
\hline
\end{tabular}

A: Restrictions on concentration and infusion fluid, B: There is no data, C: Appearance of precipitation, D: Appearance of turbidity, particle formation and/or color, E: Chemical decomposition

compatibility as the main potential DI $[7,11,15,16]$, including Kalikstad et al. [9] who, when analyzing the compatibility of medicines in NICUs, found $60 \%$ of drug combinations with unknown compatibility. However, the authors limited themselves to analyzing potential DI

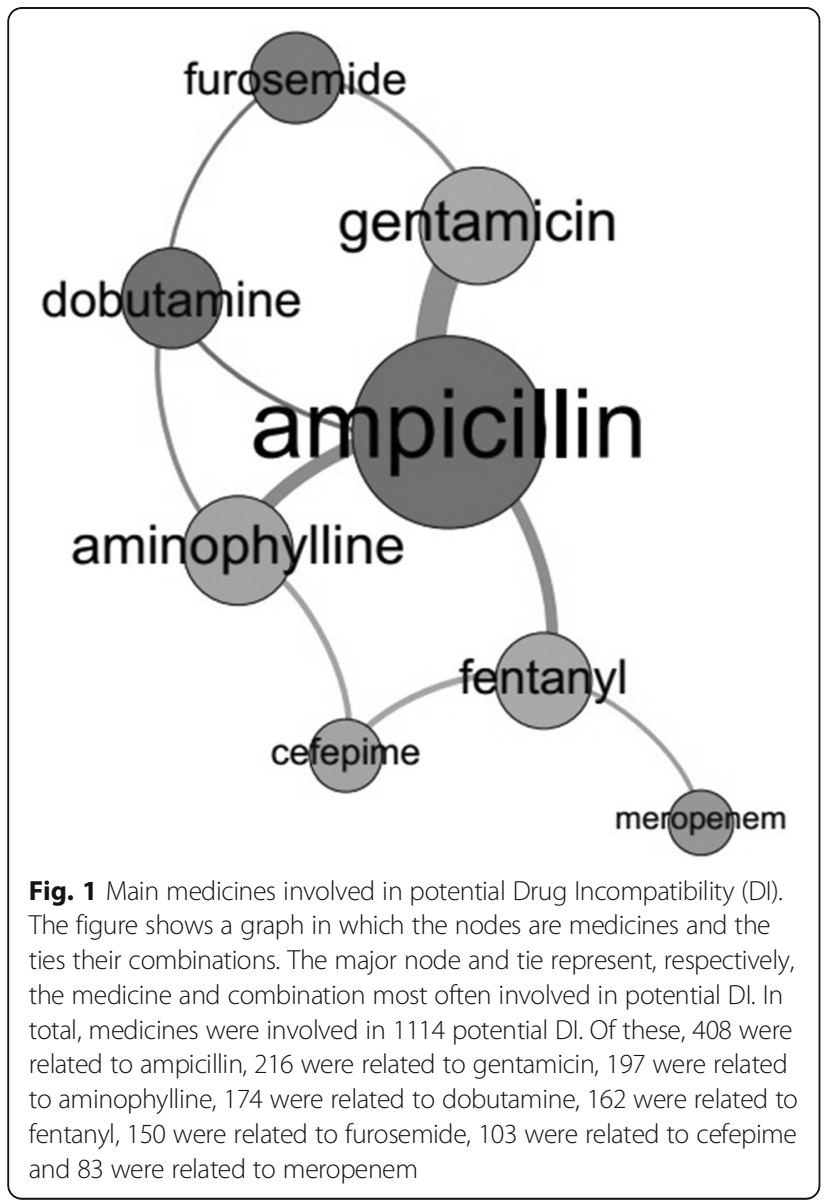

related to the most frequent medicines, while we have described the potential combinations of all drugs.

The restricted compatibility observed in most drug combinations in the NICU shows that many compatibility studies have conflicting results and are not very clear, therefore questionable as to quality. These studies are old and inadequate for clinical practice, present different methods and technique, and disregard important parameters such as brand, diluent and concentration of medicines [8]. In addition, the off-label use of medicines in neonatology and the profusion of new products on the market contribute to discordant information and data scarcity $[2,9]$.

Through network analysis, we were able to map the most relevant medicines to potential DI in the NICU. In this regard, ampicillin clearly plays a central role in the occurrence of potential DI, especially considering its prescription together with gentamicin, dobutamine and aminophylline. Although ampicillin is one of the most commonly used NICU drugs [17], the main problems related to its preparation and administration are $\mathrm{pH}$-sensitive solubility and strong hydrolysis in the presence of dextrose, which requires a lot of attention from the healthcare team [18].

There are three strategies to avoid the simultaneous administration of potentially incompatible drugs: 1) administration of drugs in different venous accesses or at different times, 2) rinsing of the infusion system with a neutral IV solution prior to the application of another drug, or 3) use of a multilumen device [1, 19]. However, the large number of medicines used in intensive therapy can make it almost impossible to administer a single medicine, in particular medicines administered through continuous infusion. On the other hand, additional vascular accesses increase the risk of infections 
and thromboembolic complications, while not administering one of the drugs compromises treatment effectiveness; therefore, in many situations, the occurrence of drug incompatibility is inevitable [8].

This study has some limitations. Our results derive only from the analysis of prescriptions, and the administration process was not directly observed in order to detect mixture of drugs and the occurrence of incompatibilities. The correspondence of actual to potential drug incompatibilities depends on local practices, on the availability of institutional treatment protocols and on the general organization of the service, for example, whether the administration of medicines is supervised by a clinical pharmacist. In addition, the data were collected in a single institution, which may restrict the generalization of our findings. However, as far as we know, this is the first prospective cohort to investigate and describe drug incompatibility in NICUs. The study design and the use of the Trissel's ${ }^{\mathrm{m}} 2$ IV Compatibility tool, gold standard in compatibility analysis [20], strengthen our results. In addition, we were able to demonstrate the applicability of the network analysis in the visualization of the drugs and pairs most involved in potential DI. Further research should be performed by direct observation of drugs administered in large populations as well as related clinical outcomes.

\section{Conclusion}

In this prospective cohort, we emphasize that potential DI are extremely common in NICU, and half of the newborns are susceptible to simultaneous administration of incompatible drugs. In addition, restricted compatibility is the main potential DI, and Ampicillin-Gentamicin is the most frequent pair. Particular attention should be given to ampicillin, gentamicin and aminophylline, as these drugs were the most commonly involved in potential DI.

\section{Abbreviations}

Cl: Confidence Interval; DI: Drug incompatibility; NICU: Neonatal Intensive Care Unit; OR: Odds Ratio

\section{Acknowledgements}

We are grateful to all pharmacists of the maternity hospital, especially to Elaine Alves, PharmD., and Tayne Cortez, PharmD., for valuable contributions in the elaboration of the research project, and Ms. Amanda Nascimento, pharmacy student, for helping in data collection and recording. We also thank all members of the NICU, physicians, physiotherapists, nurses and auxiliaries.

\section{Funding}

This study received fund by National Counsel of Technological and Scientific Development (CNPq).

\section{Availability of data and materials}

All data generated or analyzed during this study are included in this published article. Additional information may be requested directly from the study authors.

\section{Authors' contributions}

$\mathrm{RL}$ worked on the study design, collection, analysis and interpretation of the data, preparation and review of the manuscript. $\mathrm{HC}$ and TC participated in the study design, collection and analysis of the data. RM and AGO contributed to the design of the study, analysis and interpretation of the data and revision of the manuscript. All authors approved the final version of the manuscript.

\section{Ethics approval and consent to participate}

The study protocol followed the norms and guidelines that regulate research involving human beings. The study was approved by the Institutional Review Board of the University Hospital Onofre Lopes (No. $580.201 / 2014$ ) and written informed consent was obtained from all legal representatives of the neonates.

\section{Consent for publication \\ Not applicable.}

\section{Competing interests}

The authors declare that they have no competing interests.

\section{Publisher's Note}

Springer Nature remains neutral with regard to jurisdictional claims in published maps and institutional affiliations.

\section{Author details}

'Department of Pharmacy, Centro de Ciências da Saúde, Universidade Federal do Rio Grande do Norte, Av. General Gustavo Cordeiro de Farias, s/n. Petrópolis, Natal, RN 59012-570, Brazil. " Maternity School Januário Cicco, Centro de Ciências da Saúde, Universidade Federal do Rio Grande do Norte, Av. Nilo Peçanha, 259. Petrópolis, Natal, RN 59012-310, Brazil.

Received: 4 June 2018 Accepted: 1 November 2018

Published online: 06 December 2018

\section{References}

1. Secoli SR, Pérez-Esquirol E, De Las Heras-Matellán MJ, Vendrell-Bosh L, Ballarín-Alins E. Incompatibilidades en la terapia intravenosa: iqué hacer para prevenirlas? Enferm Clín. 2009;19:349-53.

2. DeMonaco HJ. Intravenous drug compatibility. Crit Care Med. 1990;18:896.

3. Newton DW. Drug incompatibility chemistry. Am J Health Syst Pharm. 2009; 66:348-57.

4. Foinard A, Décaudin B, Barthélémy C, Debaene B, Odou P. Impact of physical incompatibility on drug mass flow rates: example of furosemidemidazolam incompatibility. Ann Intensive Care. 2012;2:28.

5. Lehr HA, Brunner J, Rangoonwala R, Kirkpatrick CJ. Particulate matter contamination of intravenous antibiotics aggravates loss of functional capillary density in postischemic striated muscle. Am J Respir Crit Care Med. 2002:165:514-20.

6. Bradley JS, Wassel RT, Lee L, Nambiar S. Intravenous ceftriaxone and calcium in the neonate: assessing the risk for cardiopulmonary adverse events. Pediatrics. 2009;123:e609-13.

7. Gikic M, Di Paolo ER, Pannatier A, Cotting J. Evaluation of physicochemical incompatibilities during parenteral drug administration in a paediatric intensive care unit. Pharm World Sci. 2000;22:88-91.

8. Kanji S, Lam J, Johanson C, Singh A, Goddard R, Fairbairn J, et al. Systematic review of physical and chemical compatibility of commonly used medications administered by continuous infusion in intensive care units. Crit Care Med. 2010;38:1890-8.

9. Kalikstad B, Skjerdal A, Hansen TWR. Compatibility of drug infusions in the NICU. Arch Dis Child. 2010;95:745-8.

10. Kanji S, Lam J, Goddard RD, Johanson C, Singh A, Petrin L, et al. Inappropriate medication administration practices in Canadian adult ICUs: a multicenter, cross-sectional observational study. Ann Pharmacother. 2013:47:637-43

11. Gaetani M, Frndova H, Seto W, Parshuram C. Concurrent intravenous drug administration to critically ill children: evaluation of frequency and compatibility. J Crit Care. 2017;41:198-203.

12. Sherwin CMT, Medlicott NJ, Reith DM, Broadbent RS. Intravenous drug delivery in neonates: lessons learnt. Arch Dis Child. 2014;99:590-4.

13. Bastian M, Heymann S, Jacomy M. Gephi: an open source software for exploring and manipulating networks; 2009. 
14. Jacomy M, Venturini T, Heymann S, et al. ForceAtlas2, a continuous graph layout algorithm for handy network visualization designed for the Gephi software. PLoS One. 2014;9:e98679.

15. Leal KDB, Leopoldino RWD, Martins RR, Verissimo LM. Potential intravenous drug incompatibilities in a pediatric unit. Einstein (Sao Paulo). 2016;14:185-9.

16. Bourhis M, Tortolano L, Lalioui S, Chardonnet F, Dufourb C, Gaudina A.

Évaluation et optimisation des pratiques de perfusion en oncologie pédiatrique. Pharm Hosp Clin. 2017;xxx:1-6.

17. Krzyżaniak N, Pawłowska I, Bajorek B. Review of drug utilization patterns in NICUs worldwide. J Clin Pharm Ther. 2016;41:612-20.

18. Trissel LA. Handbook on injectable drugs. 16th ed. Bethesda: American society of health-system pharmacists; 2011.

19. Perez $M$, Décaudin B, Foinard A, Barthélémy C, Debaene B, Lebuffe G, et al, Compatibility of medications during multi-infusion therapy: a controlled in vitro study on a multilumen infusion device. Anaesth Crit Care Pain Med. 2015;34:83-8.

20. De Giorgi I, Guignard B, Fonzo-Christe C, Bonnabry P. Evaluation of tools to prevent drug incompatibilities in paediatric and neonatal intensive care units. Pharm World Sci. 2010;32:520-9.

Ready to submit your research? Choose BMC and benefit from:

- fast, convenient online submission

- thorough peer review by experienced researchers in your field

- rapid publication on acceptance

- support for research data, including large and complex data types

- gold Open Access which fosters wider collaboration and increased citations

- maximum visibility for your research: over $100 \mathrm{M}$ website views per year

At BMC, research is always in progress.

Learn more biomedcentral.com/submissions 